Original Research Paper

\title{
Scattering of Rubella IgG Titer in Cytomegalovirus IgG Sero- Positive Adult Women in Bangladesh
}

\author{
${ }^{1}$ P.K.M. Moyen Uddin, ${ }^{1}$ Tusar Roy, ${ }^{2}$ M. Jabunnisa, \\ ${ }^{3}$ Md. Saiful Islam, ${ }^{4}$ Yearul Kabir, ${ }^{5}$ Md. Matiar Rahman and ${ }^{6}$ Nurul Absar \\ ${ }^{I}$ Department of Biochemistry, Primeasia University, Dhaka, Bangladesh \\ ${ }^{2}$ Department of Public Health Nutrition, Primeasia University, Dhaka, Bangladesh \\ ${ }^{3}$ Department of Clinical Laboratory, Dhaka Hospital Ltd., Bangladesh \\ ${ }^{4}$ Department of Biochemistry and Molecular Biology, University of Dhaka, Bangladesh \\ ${ }^{5}$ Department of Biochemistry and Molecular Biology, Rajshahi University, Bangladesh \\ ${ }^{6}$ Department of Biochemistry and Biotechnology, USTC, Bangladesh
}

Article history

Received: 22-05-2015

Revised: 07-11-2015

Accepted: 04-01-2016

Corresponding Author:

P.K.M. Moyen Uddin

Department of Biochemistry,

Primeasia University, Dhaka,

Bangladesh

Email: moyen.uddinpk@primeasia.edu.bd

\section{Introduction}

Cytomegalovirus (CMV) infection is frequently seen in developing countries and it is commonly Sero-Positivity
Abstract: Primary infections caused by rubella and Cytomegalovirus (CMV) can front-runner to thoughtful complications in pregnancy. Rubella and CMV screening of adult women is not consistently conceded out in Bangladesh. The aim of this study was to determine the prevalence of rubella infection among CMV IgG sero-positive adult women. Throughout this study we reviewed the testing records of CMV IgG sero-positive adult women aged of 17-36 years who presented by random at immunology laboratory records at Dhaka Hospital Ltd., Bangladesh. Between January, 2014 to July, 2014, 51 anti-CMV IgG positive adult women were included and retrospectively evaluated in this study. The mean age of the selected CMV IgG sero-positive adult women in this study was $24.67 \pm 5.46$ years. The highest sero-positivity for the anti-CMV IgG $(15,41.2 \%)$ and antiRubella IgG $(14,37.25 \%)$ were documented in $22-26$ age group and followed by $29.4 \%$ for CMV IgG and $27.45 \%$ for Rubella IgG in $17-21$ age group. The mean CMV IgG titer was $289.49 \mathrm{IU} \mathrm{mL}^{-1}$ for 17-21 age group while $99.03 \mathrm{IU} \mathrm{mL}^{-1}$ in Rubella IgG titer, $248.65 \mathrm{IU} \mathrm{mL}^{-1} \mathrm{CMV}$ IgG titer for 22-26 age group whereas $103.21 \mathrm{IU} \mathrm{mL}^{-1}$ Rubella $\mathrm{IgG}, 275.06 \mathrm{IU} \mathrm{mL}^{-1}$ CMV IgG titer and $116.36 \mathrm{IU} \mathrm{mL}^{-1}$ Rubella IgG titer for 27-31 age group and $301.60 \mathrm{IU} \mathrm{mL}^{-1} \mathrm{CMV}$ IgG titer although $109.76 \mathrm{IU} \mathrm{mL}^{-1}$ Rubella IgG titer for 32-36 age group. The median of CMV IgG titer and Rubella IgG titer were $233.80 \mathrm{IU} \mathrm{mL}^{-1}$ and $68.20 \mathrm{IU} \mathrm{mL}^{-1}$ with 298.00 and $126.90 \mathrm{IU}$ $\mathrm{mL}^{-1}$ of $75 \%$ percentile respectively. Although high prevalence of CMV IgG and Rubella IgG were found (41.2 and 37.25\%) in 22-26 age group, but the highest mean CMV IgG titer (301.60 $\left.\mathrm{IU} \mathrm{mL}^{-1}\right)$ found in 32-36 age group while highest mean Rubella IgG titer $\left(116.36 \mathrm{IU} \mathrm{mL}^{-1}\right.$ ) was found in $27-31$ age group. So, Deterrent actions must be taken to lessening the mortality and morbidity related to congenital rubella and CMV infections in fetus. The rubella and CMV status should be investigated before pregnancy and seronegative females can be recommended for vaccination.

Keywords: Secondary Infection, Maternal Infection, Immunoglobulin IgG, infection, especially in early pregnancy, infectious mononucleosis in young subjects and severe infections in immunocompromised patients. Inherited CMV 
infection may result in hepatitis, hepatos-plenomegaly, petechial skin eruption, multiple organ failure, microcephaly, mental retardation, chorioretinitis and cerebral calcification (Crumpacker and Zhang, 2010; Tekerekoğlu et al., 2003; Akinci et al., 2007). Rubella is a severe viral infection seen in children and adults. It is characterized by skin eruption, fever and lymphadenopathy. Besides, it can cause inherited rubella syndrome in the children of pregnant patients. It may clue to many irregularities regarding heart, eye, central nervous and haematopoietic systems in the infected newborn (Efe et al., 2009; Gershon, 2010; Aydin et al., 2009). Maternal Cytomegalovirus (CMV) is the commonest viral infection in perinatal period and it is the principal cause for inherited CMV infection with a permanent hearing, vision loss and neurological impairment (Alford et al., 1990; Tabatabaee and Tayyebi, 2009; Cannon et al., 2010). While CMV has asymptomatic infection, rubella infection is mild or self -limiting disease, transmitted through respiratory system and to growing fetus through placenta (Ojala et al., 1973). Although, incidence of rubella infection is abridged worldwide, some African countries like Mozambique still has a high incidence (95.3\%) (Barreto et al., 2006; Robertson et al., 2003). Rubella vaccine is costeffective and cost-beneficial, therefore since year 2000 WHO proposed an introduction of rubella vaccine program in each country (Elnahas et al., 2003).

There is no published data concerning rubella seroprevalence in CMV IgG sero-positive adult women in Bangladesh. The basic data concerning rubella infections in adult women is important for health planners and care providers. Thus, the aim was to investigate seroprevalence for rubella infections among CMV IgG sero-positive adult women in Bangladesh. This work was the part of collaborative projects between Primeasia University and Dhaka Hospital Ltd., Bangladesh.

\section{Materials and Methods}

This was a cross-sectional study conducted at Dhaka Hospital Ltd. Bangladesh during the period of Jan-July 2014. Throughout this study we reviewed the testing records of CMV IgG sero-positive adult women aged of 17-36y were approached to participate in the study. Four age groups of CMV IgM positive patients were generated namely 17-21y, 22-26y, 27$31 \mathrm{y}$ and 32-36y respectively. Five mls of blood were collected in plain tubes, allowed to clot and centrifuged at room temperature. Enzyme-Linked Immunosorbent Assay (ELISA) was used for CMV and rubella (IgG) using commercial diagnostic kits
(DRG Instruments GmbH. Germany). Quantitative analysis for CMV and rubella IgG were performed and the assay result interpreted as $\mathrm{IU} / \mathrm{ml}$. The manufacturer's instructions were followed for the cutoff points, which was $<9 \mathrm{IU} \mathrm{mL}^{-1}$ for $\mathrm{CMV} \mathrm{IgG} \mathrm{while}<10$ IU $\mathrm{mL}^{-1}$ was considered negative for rubella $\mathrm{IgG}$, respectively. Between January, 2014 to July, 2014, 51 anti-CMV IgG positive adult women were included and retrospectively evaluated in this study.

\section{Statistics}

Data were entered in the computer using SPSS for windows version 16.0 and double checked before analysis. $P$ value $<0.05$ was considered significant.

\section{Results}

Frequency of anti-CMV IgG Titer among AdultNon Pregnant Women

The sero-positivity for anti-CMV IgG was documented with age stratifications including 17-21, 22-26, 27-31 and 32-36 years age groups and showed $41.2 \%(\mathrm{n}=21)$ highest positivity in $22-26$ age group whereas $32-36$ age group with lowest positivity frequency, $11.8 \%(n=6)$, as shown in Fig. 1 .

Even if, 22-26 age group assigned with highest CMV IgG positivity but the highest mean CMV IgG titer (301.60 IU mL $\mathrm{mL}^{-1}$ ) was found in 32-36 age group. With utilization of paired sample $t$ test between age group and anti-CMV IgG titer, it was found non-effective relationship of anti-CMV $\mathrm{IgG}$ with age groups and $\mathrm{p}$ value was $>0.05$. As shown in Fig. 2 .

\section{Prevalence of Anti-Rubella IgG Titer among Adult- Non Pregnant Women}

In Fig. 3, the sero-positivity for anti-Rubella IgG was found in $46(90.19 \%)$ while $9.81 \%$ (5) was recorded as sero-negativity of anti-Rubella IgG. The highest anti-rubella IgG positivity was acknowledged in 22-26 age group $(37.25 \%, \mathrm{n}=19)$ however the lowest sero-positivity was counted in 32-36 age group $(9.81 \%, \mathrm{n}=5)$. The rates of sero-positivity and negativity of anti-rubella $\operatorname{IgG}$ are also presented in Fig. 3.

In comparing to anti-CMV IgG positivity and titer distribution, the rates of anti-rubella $\mathrm{IgG}$ positivity showed different prevalence patterns, presented in Fig. 4 and the highest anti-rubella IgG titer was found in 27-31 age group (116.36 IU mL $\mathrm{mL}^{-1}$ ) while 99.03 IU $\mathrm{mL}^{-1}$ was documented in 17-21 age group adult women. Figure 2 explained the anti-rubella IgG titer distribution of 51 adult-non pregnant women selected in this study. 


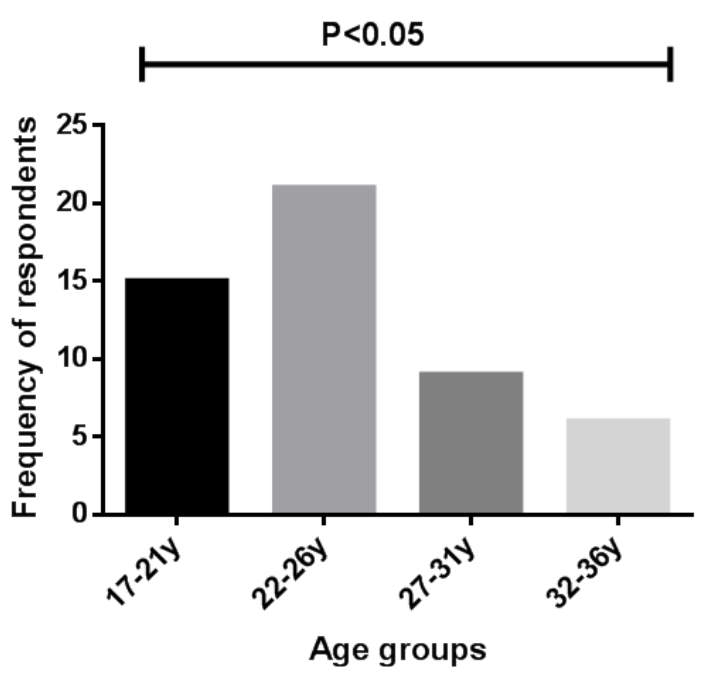

Fig. 1. Frequency of CMV IgG positive adult women in four different age groups

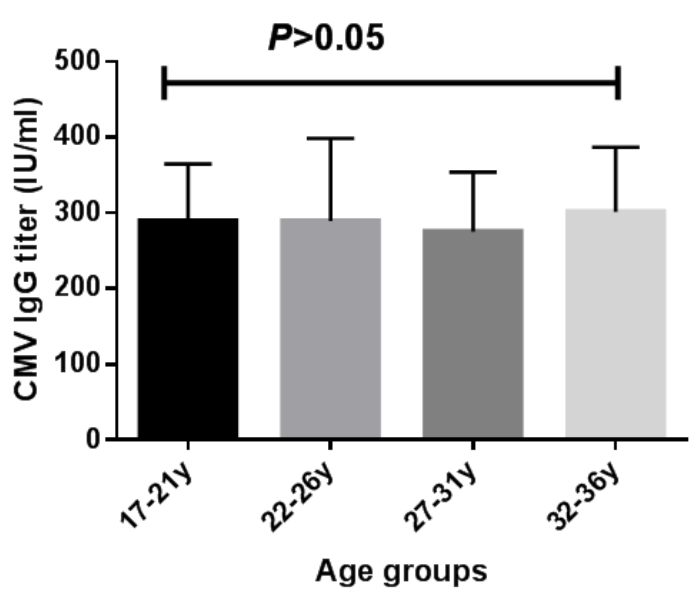

Fig. 2. Scattering of anti-CMV IgG titer among adult women with age stratifications

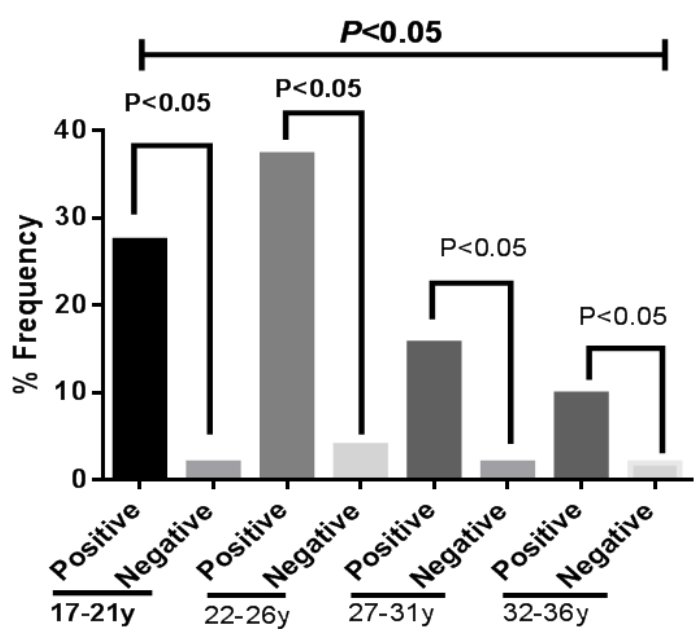

Fig. 3. \% Frequency of anti-Rubella $\operatorname{IgG}$ distribution among adult women

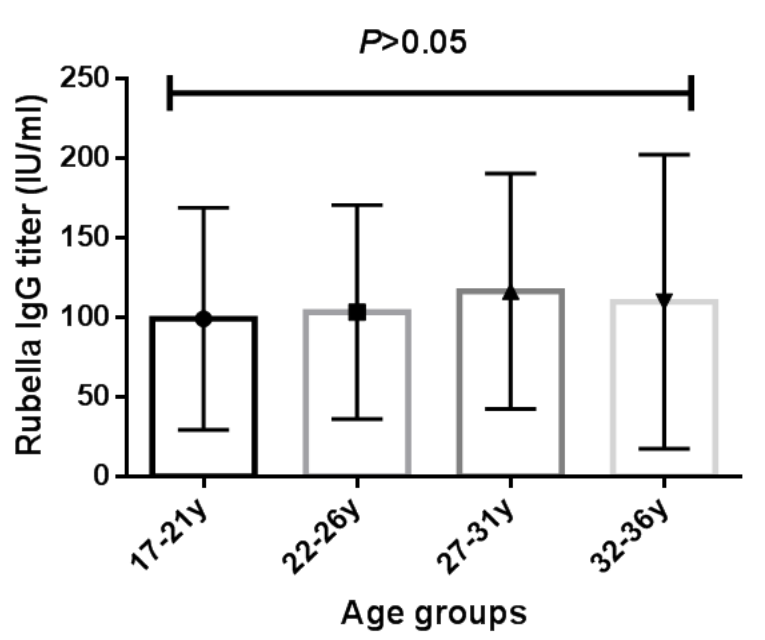

Fig. 4. Scattering of anti-Rubella IgG antibody titer among adult women with age stratifications

\section{Discussion}

To our knowledge this the first published data in Bangladesh concerning epidemiology of rubella infection among CMV IgG positive adult women. In the current study, the prevalence of Rubella IgG seropositivity was $90.19 \%$ in CMV IgG positive adult women. Middle age group 22-26y showed highest incidence of CMV IgG positivity $(41.2 \%, \mathrm{p}<0.05)$ and rubella IgG positivity $(37.25 \%, \mathrm{p}<0.05)$. However, much higher prevalence of CMV was reported in South East Asia (Taechowisan et al., 2007), while European countries show low prevalence (Picone et al., 2009).

In this study, it found that the scattering of CMV IgG and rubella IgG titer were statistically non-significantly $(p>0.05)$ with age specifications.

Likewise, low socio-economic status has been found as a strong risk factor for acquisition CMV infection (Bukbuk et al., 2002). Nevertheless in Bangladesh it is difficult to investigate the socioeconomic status of these adult women because the culture is based on generous hospitality attitude toward guest and family members who usually lives in extended families.

The current study has many limitations; one of these we did not use Polymerase Chain Reaction (PCR) of the viral DNA isolation. The other limitation is the lack of follow-up for these women in order to document seroconveration and to detect fetal infections.

\section{Conclusion}

This study shows the prevalence of $90.19 \%$ of rubella infections among CMV IgG sero-positive adult women in Bangladesh. Rubella vaccine is endorsed for adult women. Additional research is required. 


\section{Author's Contributions}

P.K.M. Moyen Uddin: Manuscript writing/data analysis.

Tusar Roy: Data collection.

M Jabunnisa: Data mining.

Md. Saiful lslam: Manuscript writing (lntroduction).

Yearul Kabir: Prepare research plan.

Md. Matiar Rahman: Review article and data analysis.

Nurul Absar: Review article and data mining.

\section{Ethics}

This article is original and contains unpublished material. The corresponding author confirms that all of the other authors have read and approved the manuscript and no ethical issues involved.

\section{References}

Akinci, P., I. Altuğlu, R. Sertöz and A. Zeytinoğlu, 2007. Rubella and cytomegalovirus infection in pregnant women in Izmir, Turkey. Turkish J. Infect., 21: 183-6.

Alford, C.A., S. Stagno, R.F. Pass and W.J. Britt, 1990. Congenital and perinatal cytomegalovirus infections. Rev. Infect. Dis., 12: 745-753. DOI: $10.1093 /$ clinids/12.Supplement_7.S745

Aydin, N., M. Eyigör, S. Kirdar, B. Gültekin and G. Evcil, 2009. Seroprevalance of rubella IgM and IgG in childbearing-aged women. Turkish J. Infect., 23: 113-6.

Barreto, J., I. Sacramento, S.E. Robertson, J. Langa and E. de Gourville et al., 2006. Antenatal rubella serosurvey in Maputo, Mozambique. Trop. Med. Int. Health, 11: 559-64.

DOI: $10.1111 / \mathrm{j} .1365-3156.2006 .01577 . x$

Bukbuk, D.N., A.U. El Nafaty and J.Y. Obed, 2002. Prevalence of rubella-specific IgG antibody in nonimmunized pregnant women in Maiduguri, north eastern Nigeria. Cent. Eur. J. Public Health, 10: 21-3. PMID: 12096678

Cannon, M.J., D.S. Schmid and T.B. Hyde, 2010. Review of cytomegalovirus seroprevalence and demographic characteristics associated with infection. Rev. Med. Virol., 20: 202-13.

DOI: $10.1002 /$ rmv.655
Crumpacker, C.S. and J.L. Zhang, 2010. Cytomegalovirus. In: Principles and Practice of Infectious Diseases, Mandell, G.L., J.E. Bennet and R. Dolin (Eds.), Churchill Livingstone, Philadelphia, ISBN-10: 0443068399, pp: 1971-87.

Efe, Ş., Z. Kurdoglu and G. Korkmaz, 2009. Seroprevalance of cytomegalovirus, rubella and toxoplasma antibodies in pregnant women of Van region. Med. J. Van., 16: 6-9.

Elnahas, A., A.S. Gerais, M.I. Elbashir, E.S. Eldien and I. Adam, 2003. Toxoplasmosis in pregnant Sudanese women. Saudi Med. J., 24: 868-70. PMID: 12939674

Gershon, A.A., 2010. Rubella Virus (German Measles). In: Principles and Practice of Infectious Diseases, Mandell, G.L., J.E. Bennet and R. Dolin (Eds.), Churchill Livingstone, Philadelphia, pp: 2127-32.

Ojala, P., T. Vesikari and O. Elo, 1973. Rubella during pregnancy as a cause of congenital hearing loss. Am. J. Epidemiol., 98: 395-401. PMID: 4746026

Picone, O., C. Vauloup-Fellous, A.G. Cordier, I. Parent Du Châtelet and M.V. Senat et al., 2009. A 2-year study on cytomegalovirus infection during pregnancy in a French hospital. BJOG, 116: 818-23. DOI: 10.1111/j.1471-0528.2009.02139.x

Robertson, S.E., D.A. Featherstone, M. Gacic-Dobo and B.S. Hersh, 2003. Rubella and congenital rubella syndrome: Global update. Rev. Panam. Salud Publica, 14: 306-15.

DOI: $10.1590 / \mathrm{S} 1020-49892003001000005$

Tabatabaee, M. and D. Tayyebi, 2009. Seroepidemiologic study of human cytomegalovirus in pregnant women in Valiasr Hospital of Kazeroon, Fars, Iran. J. Matern. Fetal Neonatal Med., 22: 517-21. DOI: 10.1080/14767050902801678

Taechowisan, T., R. Sutthent, S. Louisirirotchanakul, P. Puthavathana and C. Wasi, 2007. Immune status in congenital infections by TORCH agents in pregnant Thais. Asian Pac. J. Allergy Immunol., 15: 93-7. PMID: 9346273

Tekerekoğlu, M.S., Z. Çizmeci, I.H. Özerol and R. Durmaz, 2003. Screening of antibodies against cytomegalovirus and rubella virus in childbearing age women. Med. J. Inonu. Univ., 10: 129-31. 